\title{
Response and resilience of Spartina alterniflora to sudden dieback
}

\author{
Amanda Marsh ${ }^{1,2} \cdot$ Linda K. Blum ${ }^{3} \cdot$ Robert R. Christian ${ }^{1} \cdot$ Elijah Ramsey III ${ }^{4}$. \\ Amina Rangoonwala ${ }^{4}$
}

Received: 3 May 2015 /Revised: 14 September 2015 / Accepted: 30 May 2016 /Published online: 25 June 2016

(C) The Author(s) 2016. This article is published with open access at Springerlink.com

\begin{abstract}
We measured an array of biophysical and spectral variables to evaluate the response and recovery of Spartina alterniflora to a sudden dieback event in spring and summer 2004 within a low marsh in coastal Virginia, USA. $S$. alterniflora is a foundation species, whose loss decreases ecosystem services and potentiates ecosystem state change. Long-term records of the potential environmental drivers of dieback such as precipitation and tidal inundation did not evidence any particular anomalies, although Hurricane Isabel in fall 2003 may have been related to dieback. Transects were established across the interface between the dieback area and apparently healthy areas of marsh. Plant condition was classified based on ground cover within transects as dieback, intermediate and healthy. Numerous characteristics of S. alterniflora culms within each condition class were assessed including biomass, morphology and spectral attributes associated with photosynthetic pigments. Plants demonstrated evidence of stress in 2004 and 2005 beyond areas of obvious dieback and resilience
\end{abstract}

Electronic supplementary material The online version of this article (doi:10.1007/s11852-016-0445-9) contains supplementary material, which is available to authorized users.

Amanda Marsh

amanda.marsh30@yahoo.com

1 Department of Biology, East Carolina University, Greenville, NC 27858, USA

2 CHA Consulting, Inc., 1901 Innovation Drive, Suite 2100, Blacksburg, VA 24060, USA

3 Department of Environmental Science, University of Virginia, Charlottesville, VA 22903, USA

4 Wetland and Aquatic Research Center, USGS, 700 Cajundome Blvd, Lafayette, LA 70506, USA at a multi-year scale. Resilience of the plants was evident in recovery of ground cover and biomass largely within $3 \mathrm{y}$, although a small remnant of dieback persisted for $8 \mathrm{y}$. Culms surviving within the dieback and areas of intermediate impact had modified morphological traits and spectral response that reflected stress. These morphometric and spectral differences among plant cover condition classes serve as guidelines for monitoring of dieback initiation, effects and subsequent recovery. Although a number of environmental and biotic parameters were assessed relative to causation, the reason for this particular dieback remains largely unknown, however.

Keywords Brown marsh $\cdot$ Marsh balding $\cdot$ Monitoring $\cdot$ Plant spectral analysis $\cdot$ Vegetation cover $\cdot$ Remote sensing

\section{Introduction}

Coastal marshes from the Gulf Coast of the United States to New England may experience sudden losses of foundation plant species, which jeopardize valued ecosystem services. Brown marsh, marsh balding, salt marsh dieback, acute marsh dieback, sudden vegetation dieback and sudden wetland dieback are all terms that are used to describe rapid (within weeks) loss of marsh vegetation with what appears to be increasing in frequency (Alber et al. 2008; Osgood and Silliman 2009; Elmer et al. 2013). During dieback, living, green culms are replaced by standing dead or bare ground. The area may be completely devoid of live culms or contain survivors at a continuum of densities. Often the loss is of Spartina alterniflora Loiseleur (smooth cordgrass), but other plant species may be involved. S. alterniflora is the dominant species within low marshes of the region and elsewhere and is considered a foundation species to marshes through fostering maintenance of elevation in the face of sea-level rise and by 
providing food and habitat among other ecosystem services (Brinson et al. 1995; Proffitt et al. 2005; Peterson et al. 2008; Baustian et al. 2012). Short-term, after the fact studies are the most frequent, but long-term studies of plant condition before, during and after dieback are needed to understand processes of response to dieback and recovery (i.e., resilience) to potentially mitigate dieback events and effectively sustain marsh ecosystem services.

Several causes of dieback have been considered. At least some of the events may be caused by a combination of factors associated with prolonged drought (McKee et al. 2004; Ogburn and Alber 2006; White and Alber 2009; Hughes et al. 2012) or inundation and waterlogging (Mendelssohn and McKee 1988; Webb and Mendelssohn 1996). Elevated salinity has been suggested as important to dieback during these droughts (McKee et al. 2004), but this has not been consistently found (Alber et al. 2008). Also linked to elevated salinity, a dieback of 111,000 ha of fresh and 411,100 ha of saline marshes in Louisiana in 2008 exhibited moderate to severe dieback within three weeks of hurricane storm surge (Ramsey et al. 2012). Pathogens and herbivory have also been posited as causes of dieback or mechanisms that foster its spread (Silliman et al. 2005; Schneider and Useman 2005; Bertness and Silliman 2008; Holdredge et al. 2008; Smith 2009; Elmer et al. 2012, 2013; Bertness et al. 2014). Although dieback has been recognized for years (Alber et al. 2008), the frequency and intensity of it may be increasing.

Most dieback sites show signs of at least some level of recovery in subsequent years. An area of dieback in South Carolina studied by de Souza and Yoch (1997) showed over $90 \%$ recovery in $2 \mathrm{y}$. The dieback that occurred in Louisiana in $2000(>100,000$ ha affected) demonstrated variable recovery. Anywhere from $0-58 \%$ live cover regrew at separate sites 15 mo after the disturbance (McKee et al. 2004). Three years after an initial dieback in Georgia, some areas had recolonized by way of rhizome extension (Ogburn and Alber 2006). Sites in New England exhibited variable recovery with some marshes remaining bare for at least 7 y (personal communication by S. Adamowicz as cited in Elmer et al. 2013). Thus, the degree of ecological resilience (sensu Holling 1996) of the plant populations is key to ecosystem recovery from the event.

Previous assessments of recovery involved the combination of in situ and remote observations (Smith 2009), experimentation with transplanting of both plants and animals (Ogburn and Alber 2006; Silliman et al. 2005; Holdredge et al. 2008), and manipulations of surface elevation (Webb and Mendelssohn 1996; Schrift et al. 2008). Observations based on leaf spectral measurements also provide plant condition indicators (Ramsey and Rangoonwala 2005, 2006). We focused on the condition of S. alterniflora within a dieback event and assessed ground cover, above-ground biomass, morphometrics, and leaf spectra.
Spectral techniques are the bases of optical remote sensing monitoring. Plant-leaf level techniques provide estimates of changes in leaf pigment compositions and concentrations that are often among the first indicators of the plant response to external changes (Ramsey and Rangoonwala 2005, 2010). Leaf absorption most directly represents pigment concentrations (Kirk 1994; Carter and Knapp 2001); however, the best evidence of pigment changes offered by optical imaging systems is plant-leaf reflectance summed over the sensor view of the canopy. Although the plant-leaf reflectance is only one contributor to the canopy reflectance (Penuelas and Filella 1998), spectral indicators at this level can be used to emphasize leaf spectral patterns in canopy reflectance (Ramsey and Rangoonwala 2006). Ramsey and Rangoonwala (2005, 2006, 2010) have shown that reflectance indicators of dieback onset and progression determined at the plant-leaf level can be successfully scaled upward to the marsh canopy, and ultimately to the satellite remote sensing platform.

A dieback event occurred in the S. alterniflora salt marsh within the Virginia Coast Reserve Long-Term Ecological Research site (VCR-LTER), USA at the Upper Phillips Creek Marsh (UPC) in the summer of 2004. For over 25 yrs., UPC has been the center of ongoing studies that provide a continuous physiological and biophysical record before and after the dieback event (e.g., Blum 1993; Keusenkothen and Christian 2004; Kirwan et al. 2012). This paper focuses on the condition of $S$. alterniflora before, during, and after the dieback event. Our objectives were to: (1) classify ground cover of S. alterniflora as an index of marsh condition, (2) establish how selected biophysical and spectral variables of live culms and leaves reflect ground cover classification, (3) document potential environmental drivers of dieback initiation, and (4) determine plant condition before and during dieback and recovery as an indication of marsh resilience. The overall goal was to formulate a resource management basis for regional monitoring and remote sensing of marsh condition directly applicable to dieback onset and progression that characterizes resilience in S. alterniflora marshes.

\section{Methods}

\section{Study site}

Upper Phillips Creek (UPC) salt marsh is an approximately 50 -ha area on the seaward side of the Delmarva Peninsula $\left(37^{\circ}\right.$ $\left.27^{\prime} \mathrm{N}, 75^{\circ} 50^{\prime} \mathrm{W}\right)$. It is part of The Nature Conservancy's Virginia Coast Reserve (VCR) and is surrounded by wetland and upland forests, wildlife preserve, and agricultural lands (Fig. 1a). The marsh is dominated by S. alterniflora in the mineral low marsh with Spartina patens (Ait.) Muhl, Distichlis spicata (L.) Greene, and Juncus roemerianus Scheele in the neighboring organic high marsh. This study 
Fig. 1 Upper Phillips Creek marsh with sampling sites. a Transects used for assessing condition class are at T1-T8. Recurring end of year biomass measurements are at S2A, S2B, and S2C. Spectral measurements were conducted at B1-B4. b Aerial photograph of the sudden dieback event. The photograph was taken in June 2004 and depicts the area that did not show much spring growth, with patches of marsh that were either devoid of plants or dominated by dead, brown S. alterniflora. Color was modified to enhance evidence of dieback
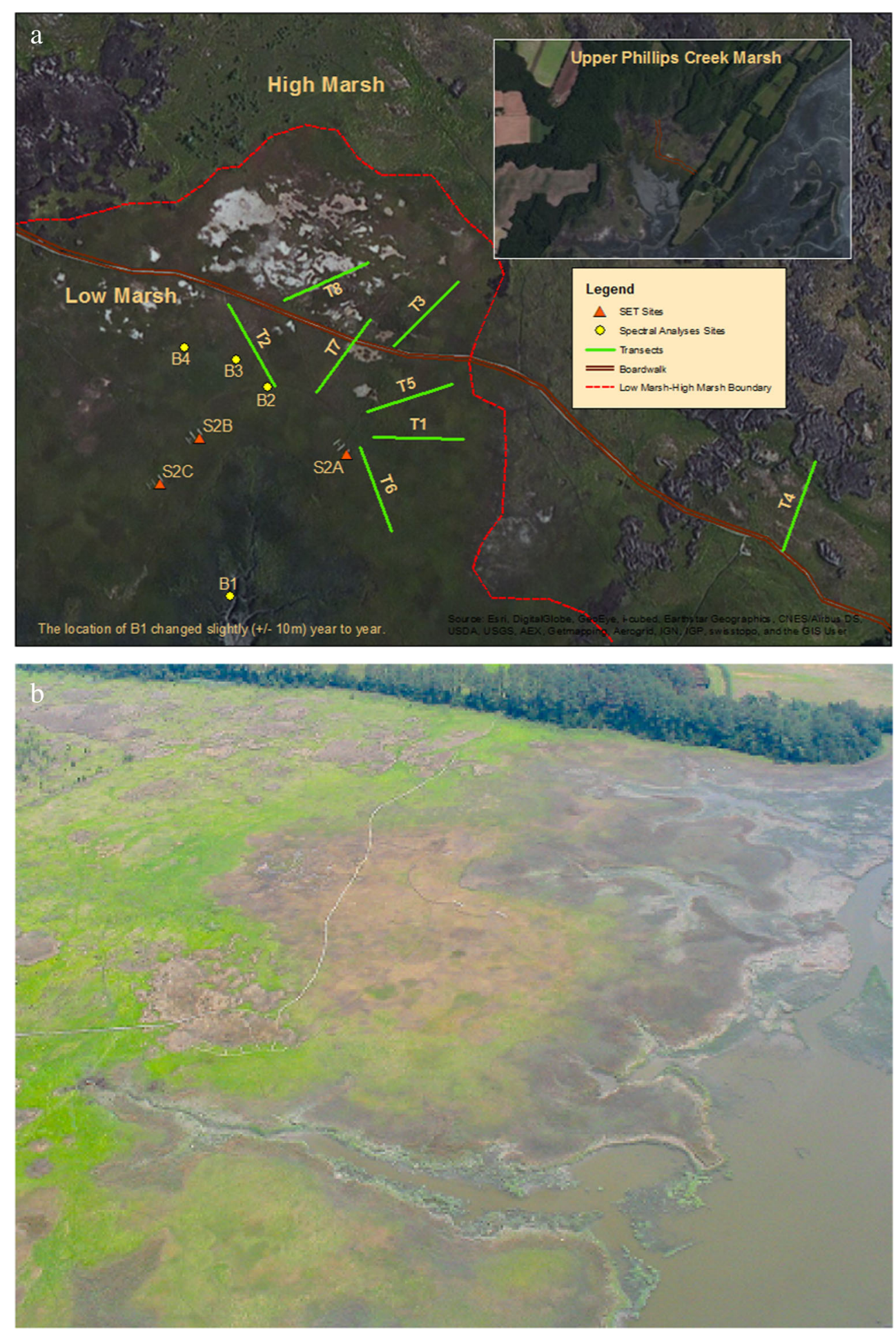

focused on the low marsh and short form of $S$. alterniflora. The elevation of low marsh is approximately $1 \mathrm{~m}$ above mean sea level and does not vary by more than a few $\mathrm{cm}$ over the platform. Phillips Creek is tidal and floods the marsh on higher high tides with salinities generally between 20 and 30 psu. The UPC marsh has been studied since the mid1980's as part of the VCR-LTER program (Blum 1993;
Brinson et al. 1995). As a result, meteorological, water quality, groundwater and marsh condition variables have been monitored for numerous years along with periodic intensive studies (http://amazon.evsc.virginia.edu/home1/index.php).

In early summer of 2004, researchers observed that an area of the low marsh's vegetation had apparently not shown much spring growth, and patches of marsh were either devoid of 
plants or dominated by dead, brown S. alterniflora (Fig. 1b). The overall area of low marsh most obviously affected by dieback was approximately 2 to 3 ha. At the center was an area of approximately 700 to $800 \mathrm{~m}^{2}$ that was most severely affected with largely bare sediment. The dieback did not occur as a single circle of brown plants or bare areas, instead it was a mosaic of patches with different degrees of dieback radiating from a bare center.

\section{Environmental drivers}

Two environmental drivers were considered as factors that might explain the occurrence of dieback in 2004: decreased frequency of flooding and drought. The marsh elevations were compared to high tide water levels to determine potential frequency of tidal flooding. Marsh elevations were established by total station GPS with benchmarks within the marsh and referenced to NAVD88. Growing season (April-August) and annual flooding frequency was determined by establishing a relationship between the elevations at UPC, expected local sea-level variation, and the nearest (i.e., $35 \mathrm{~km}$ ) NOAA tide gauge with a long-term and certified record (Kiptopeake, VA $\left.\left(37^{\circ} 10.0^{\prime} \mathrm{N}, 75^{\circ} 59.3^{\prime} \mathrm{W}\right)\right)$. The period of record was 1997 to 2012. Hourly precipitation measurements were obtained from the NOAA Climate Data Center (http://cdo.ncdc.noaa.gov/ $u l c d / U L C D)$ for the Accomack County Airport (MFV) at Melfa, Virginia $\left(37^{\circ} 38^{\prime} 57.48^{\prime \prime} \mathrm{N}, 75^{\circ} 44^{\prime} 28.74^{\prime \prime} \mathrm{W}\right) ; 22 \mathrm{~km}$ from UPC. These data were used to calculate rainfall for annual growing season (April through August) and annually for the period 1986-2012. The airport is approximately $22 \mathrm{~km}$ north of the study site, but precipitation results there are highly correlated to results from shorter term measurements on site.

\section{Distribution of vegetation condition}

Four 30-m transects (T1-T4) were established within the marsh in 2004, such that each transect included three condition classes of marsh: healthy, intermediate, and dieback $y c=10$ ? $>$ (Fig. 1a). In 2005, four more transects (T5-T8) were established to include all condition classes. To categorize and classify transect ground cover, observers walked parallel to, but $1 \mathrm{~m}$ offset, from transects and noted the condition class. This information was converted to proportions of transect length represented by each condition class and change in class from one year to another. Seven of the eight transects were revisited in June 2012 (all but T4) and were measured for condition class. Condition classes were categorized as 'dieback' if the ground cover of live and dead plants was $25 \%$ or less and $>75 \%$ was bare soil. It was considered 'intermediate' from $26 \%$ to $85 \%$ live and dead plant cover. An area was considered 'healthy' at any plant ground cover over $85 \%$. S. alterniflora was near monoculture in these transects except for T4, which reached into a transitional zone with the high marsh containing S. patens and Salicornia virginica $\mathrm{L}$.

The central area of the dieback was bare from the earliest observation. We estimated the area of the bare area in 2005, 2006 and 2012 by making multiple measurements of distances between the borders of vegetation across the bare area. These measurements were made at different angles and across different regions of the bare area. Angle and position were determined from stakes at fixed points outside the area. This information was graphed, and resultant areas of "bare" portion calculated.

\section{Elevation}

Elevations were measured along the 8 transects in August of 2006 using a laser level and referenced to NAVD88. Three replicates were taken per condition class per transect totaling 72 measurements for all conditions. The $0-\mathrm{m}$ and $30-\mathrm{m}$ endpoints for each transect were also measured, totaling 16 additional measurements.

\section{Recurrent end of year biomass}

Annual harvesting for end of the year (i.e., end of growing season in mid-August) above-ground biomass of marsh plants (EoYB) have been collected at UPC since 2001 as part of the VCR-LTER long-term core observations. This information provided documentation of dieback effects beyond the transects. Three of the EoYB sampling sites were located in the low marsh, in (S2A, Fig. 1a) or near the dieback area (S2B, S2C; Fig. 1a). Dieback was not obvious at sites S2B and S2C. To collect an EoYB sample, one $0.0625-\mathrm{m}^{2}$ quadrat was tossed haphazardly approximately $5-10 \mathrm{~m}$ to either side of the three permanently marked sites (i.e., 2 quadrats per site). We included EoYB data through 2011, the most recent year processed. Aboveground plant material was clipped and returned to the laboratory for freezing $(-20 \mathrm{C})$ until analysis. Plants were sorted by species and by live (i.e., any green on culm) or dead (i.e., all brown) status. Sorted materials were dried at $\sim 80-90{ }^{\circ} \mathrm{C}$ to a constant weight and weighed to the nearest $0.01 \mathrm{~g}$.

In the fall of 2004, 2005, and 2006, EoYB harvests were also taken from each dieback transect. Samples were taken by haphazardly tossing a $0.0625-\mathrm{m}^{2}$ quadrat into an area designated as one of the condition classes. Two samples were taken per condition class per transect for a total of 48 clippings per year and processed as above. The density of culms from each category was also determined.

\section{Plant morphometrics}

The morphology of $S$. alterniflora culms was assessed using tagged plants to examine how surviving plants within affected 
areas may have had altered characteristics from those in healthy areas. Morphological traits were determined as the height of the culm measured to the tip of the inner most leaf, the total number of leaves and the number of dead leaves. Culms were tagged with labeled rings cut from numbered Tygon tubing. Morphological traits were determined on June 8, 2005, and re-evaluated on July 13 and August 18, 2005. Four live plants were tagged in each of the three condition classes along transects 5 to 8 (48 plants in all). All tagged plants were initially $<30 \mathrm{~cm}$ tall.

On August 18, 2005, after field measurements, separate and representative culms were harvested and treated similarly. These culms were returned to the laboratory, measured for morphological traits, individually dried at $80^{\circ} \mathrm{C}$ and weighed to the nearest $0.01 \mathrm{~g}$ for biomass per culm estimates.

\section{Collection strategy for spectral analyses}

Spectral analyses were conducted each summer from 2004 until 2007. Sample collection entailed extracting 15 to 20$\mathrm{cm}$ diameter plugs containing whole $S$. alterniflora plants. The strategy for developing the spectral indicators relied on collection and analyses of plant-leaf samples from two locations. The first location was within marsh that visibly retained full canopy cover although less than 50-m from heart of the dieback. Sites B2, B3, and B4 were on the marsh platform while $\mathrm{B} 1$ was situated at the apex of the tidal channel hydraulically connected to the marsh platform sites (Fig. 1a). Analyses of samples collected at these non-dieback sites were used to determine whether the dieback event could be detected and changes monitored even though the dieback was not visually apparent. The second location was situated in the dieback area. Samples were collected at dieback, intermediate, and healthy marsh locations along transects T5, T6, T7, and T8 in 2005 when dieback was evident, and again along transects T5, T6, and T7 in 2007 at dieback recovery.

\section{Plant-leaf spectral measurements}

Spectral analysis of plant samples followed methods of Ramsey and Rangoonwala (2005). At each site (B1-B4) and transect-condition class (transects T5, T6, T7, and T8), four to 8 groups of leaves were collected from plant samples, each containing 3 to 5 of the visibly greenest leaves for spectral analysis. Using a diffuse sphere, spectral measurements were obtained of the leaf adaxial surfaces immediately following the detachment of leaves from the plant (LI-COR 1984, Spectron Engineering, Inc. n.d.) (Electronic Supplemental Material). Replicate spectral measurements of each leaf sample were used to create individual sample averages and variance statistics that were subsequently combined to form a mean reflectance spectrum for each site or transect-condition per year (Ramsey and Rangoonwala, 2005).

\section{Spectral broadband ratios and pigments}

Spectral band ranges used in the comparison incorporated the visible (VIS) bands, $440-465 \mathrm{~nm}$ (blue), 548-554 nm (green), 669-675 nm (red), 698-702 nm (red-edge), and near infrared (NIR) 770-780 nm reflectance ranges, based on previous work (Ramsey and Rangoonwala 2004, 2005). Blue and red bands more represent changes at the peaks of the chlorophyll and accessory pigment absorptions, while green and red-edge bands reflect changes in the tails; thus, green and red-edge are most sensitive to early changes and blue and red to more sustained changes in pigment absorption or concentration (Gitelson et al. 1996; Ramsey and Rangoonwala 2005). Changes in NIR dominantly indicate changes in the leaf internal structure and water content (e.g. Penuelas and Filella 1998).

Spectral band ratios were calculated to provide plant condition indicators that are amenable to most current remote sensing sensors. We applied two widely used spectral band ratios, also termed vegetation indicators (VI), the NIR to red VI reflectance ratio (e.g., Penuelas and Filella 1998; Huete 2012) and the green to red VI reflectance ratio (Gitelson et al. 2003; Ramsey and Rangoonwala 2005, 2006) to assess further green and red responses to dieback.

To most directly determine pigment concentration changes, we applied predictive relationships based on the plant-leaf reflectance spectra (Gitelson et al. 2003). The pigments concentrations calculated were chlorophyll and carotene.

\section{Statistical analyses}

Differences within response variables among condition class, time and location were assessed using SPSS 19 software. We used general linear regression models with post-hoc testing of differences for conditions when sampling was considered at a single time. Data transformations were generally not necessary to control variance among conditions. We used repeated measures analysis when sampling occurred at multiple times: specifically mixed linear models and Bonferroni post-hoc tested differences in means between condition classes and years. EoYB sampling extended across 11 years, and we tested if the results from 2004 were different from those of other years.

The mean and standard deviation were calculated for the blue, green, red, NIR, NIR/red, NIR/green and estimated chlorophyll concentrations within each condition class across all transects. These univariate statistics did not include propagated error associated with each spectral band, ratio, or estimate. Each spectral band or index from transects during the 2005 sampling was analyzed for differences among condition class. We used two-way ANOVAs (condition class and transect) without replication with post-hoc LSD pairwise comparisons among condition classes.

The ability of each spectral index to discriminate condition classes was considered. We calculated the difference between 
index results for each pair of condition classes (e.g., dieback, intermediate, healthy) and divided the difference by the grand mean (mean across all conditions) for the index. We inferred that the discriminatory power of the index increased with larger percentage differences. The absolute values of the three calculated $\%$ differences were then summed for an indicator of overall discrimination.

\section{Results}

\section{Weather and tide frequency}

The dieback was recognized in early summer 2004 and appeared to result from poor growth during the spring of 2004, rather than rapid senescence or death during the summer of 2004. The frequency of tidal flooding of the $S$. alterniflora marsh was far less than semi-diurnal. The number of high tides per year reaching the area between 1997 and 2012 ranged from approximately 5 to $20 \%$ of the annual number of diurnal, high tides (Fig. 2a). Both annual and growth-seasonal flooding frequency was low in 2001, 2002 and 2004 with more normal frequency in 2003. Rainfall during the growing season (April to August) varied from 50 to nearly $200 \mathrm{~mm}$ per year from 1986 until 2012 (Fig. 2b, c). While 2002 was a slightly drought year, 2003 and 2004 had above average rainfalls. The variation across the period of record shows no indication that weather in either 2003 or 2004 was particularly severe.

One major weather event did occur in fall 2003, Hurricane Isabel (Hovis et al. 2004). This hurricane made landfall on September 18 approximately $300 \mathrm{~km}$ south of UPC near Beaufort, NC and moved northwest. Although it was a category 1 or 2 hurricane at the time of landfall, it produced considerable storm surge along the North Carolina and Virginia coasts. Storm surge overtopped the meteorological station at UPC, so no direct measures of water level were available. At the Chesapeake Bay Bridge Tunnel about $50 \mathrm{~km}$ south of UPC, maximum levels were $2.3 \mathrm{~m}$ above mean low low water and $1.41 \mathrm{~m}$ above mean high high water. A tide gage at Redbank, a few km from UPC and maintained by the VCRLTER recorded levels of $2.7 \mathrm{~m}$, the highest level for the month by at least $0.4 \mathrm{~m}$. (http://amazon.evsc.virginia.edu/data/ metdata/tide/index.html).

\section{Elevation}

There were significant differences in measured elevations among the condition classes $(p<0.001)$ and also among transects $(p<0.001)$. There was no significant condition*transect ( $p=0.210)$ interaction. Averaging all transects, the lowest average elevation relative to mean sea level was found in the dieback condition $(0.966 \pm 0.044 \mathrm{~m})$ (mean and standard deviation), and the highest in the healthy condition
$(0.996 \pm 0.053 \mathrm{~m})$. The average \pm standard deviation of the intermediate condition fell between the two other conditions $(0.980 \pm 0.043 \mathrm{~m})$. A Tukey's post hoc test showed that Transect 4, located in the high/low marsh transition, had significantly higher elevations than the other low marsh transects.

\section{Tracking dieback progress through ground cover}

Recovery was tracked through the changes in ground cover of condition classes along transects (Fig. 3). Results from individual transects are provided in Fig. 3 because of unequal sample sizes over time, to highlight the similarities among transects and to allow comparison with transect-specific spectral data. From 2004 until 2005, when the original four transects were categorized, there was very little regrowth. The four new transects had patterns of cover class similar to those of the initial transects. However, by 2006, there was considerable regrowth of $S$. alterniflora into dieback areas in all 8 transects. Regrowth included an average $27 \%$ increase in healthy areas from 2005 to 2006 and complementary decreases in other categories. For 2006, an additional category 'standing dead' was added that accounted for shoots that prematurely browned during that summer (shown at top of stacked bars in Fig.3). These 'standing dead' areas were in areas along transects that were healthy in 2005. Between 2006 and 2007, there was an additional $29 \%$ increase in the healthy areas within the eight transects and corresponding decreases in area categorized as having plants in intermediate or dieback condition (Fig. 3). Marsh area categorized as 'standing dead' in 2006 either recovered or was converted to 'dieback' by 2007. Overall dieback areas decreased from 42 to $10 \%$ along transects from 2004 to 2007 and healthy areas increased from 21 to $77 \%$. By 2012, the dieback class was observed along only 3 of the 7 transects observed, ranging from $5 \%$ in T3, to $8 \%$ in T7, to $34 \%$ in T8. Transects 7 and 8 neighbored an extensive bare area containing numerous pools near the transition to high marsh. Four transects contained completely healthy marsh. The average healthy class made up $92 \%$ of the 7 transects measured in 2012 .

Although the dieback condition was defined as containing less than $25 \%$ living plants, the center of the dieback area was almost completely devoid of living or standing dead culms by the time observations were begun in 2004. The area of this bare core was $721 \mathrm{~m}^{2}$ in 2005 and $700 \mathrm{~m}^{2}$ in 2006. A bare area remained in 2012 but had decreased to $13 \mathrm{~m}^{2}$ or only $2 \%$ of the original area.

\section{End-of-year-biomass (EoYB)}

\section{Recurring measures of low marsh EoYB}

Three sampling sites of the routine EoYB study were near transects within the UPC low marsh, and one sampling site 
Fig. 2 Multi- year records of the number of tides flooding the dieback area annually and during the growing season (a), comparison of precipitation amounts during the growing season and annually (b), and detail of growing season rainfall (c). The growing season is defined as April to August for tides and precipitation. In all panels, gray bars represent annual data and black bars represent growing season data
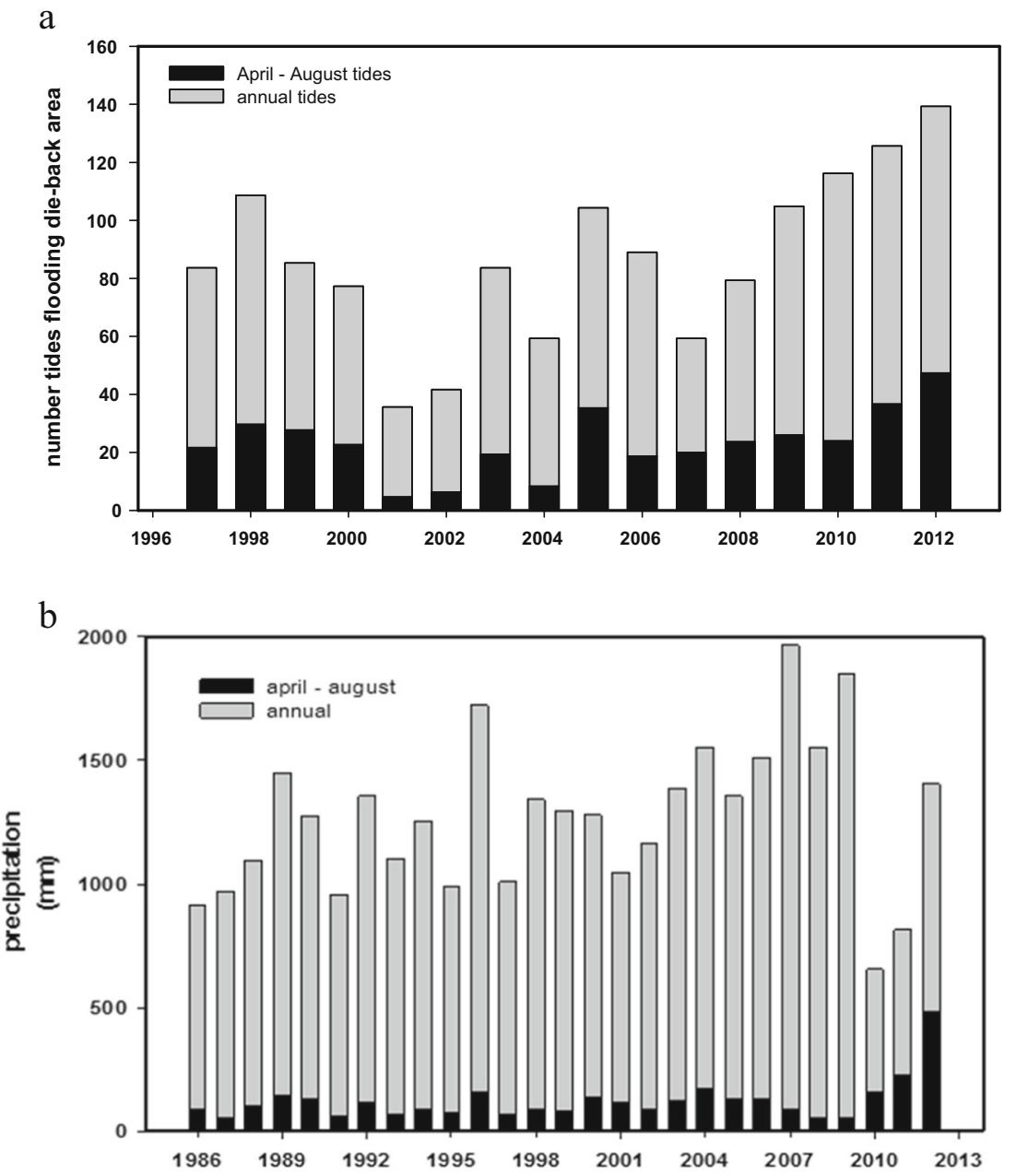

$\mathrm{c}$

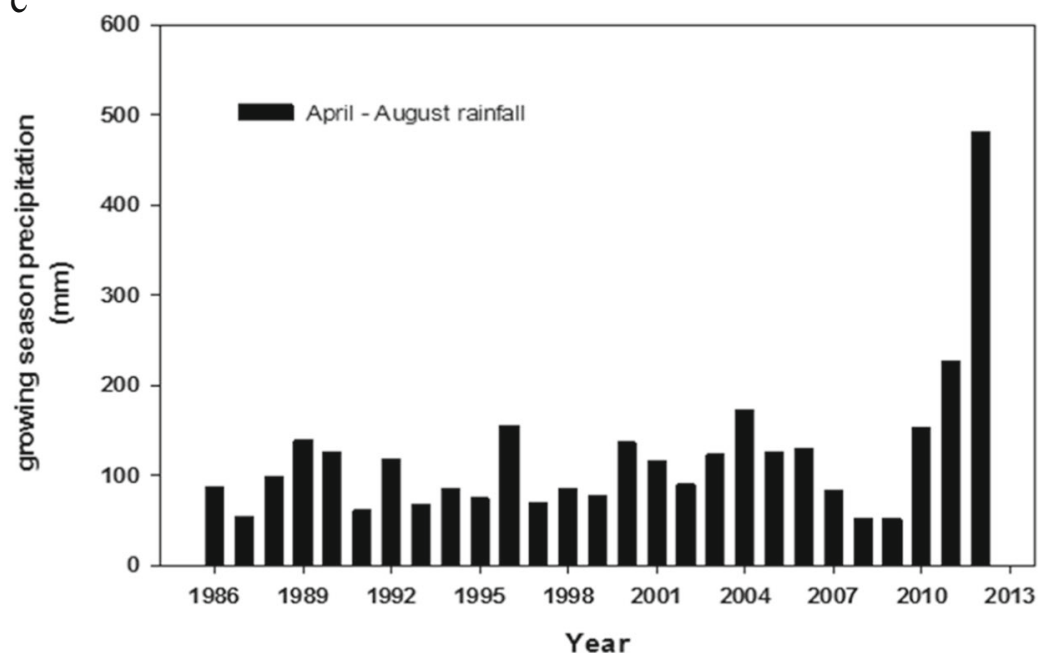

was directly within the dieback in 2004 (Fig.1a). $S$. alterniflora was usually the single dominant species throughout all years of sampling, and therefore only biomass of this species are presented. Mean \pm standard deviation of live EoYB for 2001 through 2011 was $528 \pm 272$ g dry mass $/ \mathrm{m}^{2}$, and annual means for all years excluding 2004 ranged from 375 (in 2006) to 1032 (in 2003) g dry mass $/ \mathrm{m}^{2}$ (Fig. 4). Live EoYB for 2004 was only $212 \pm 173$ g dry mass $/ \mathrm{m}^{2}$, the lowest for the period of record. Mixed linear regression analysis yielded significant differences among 


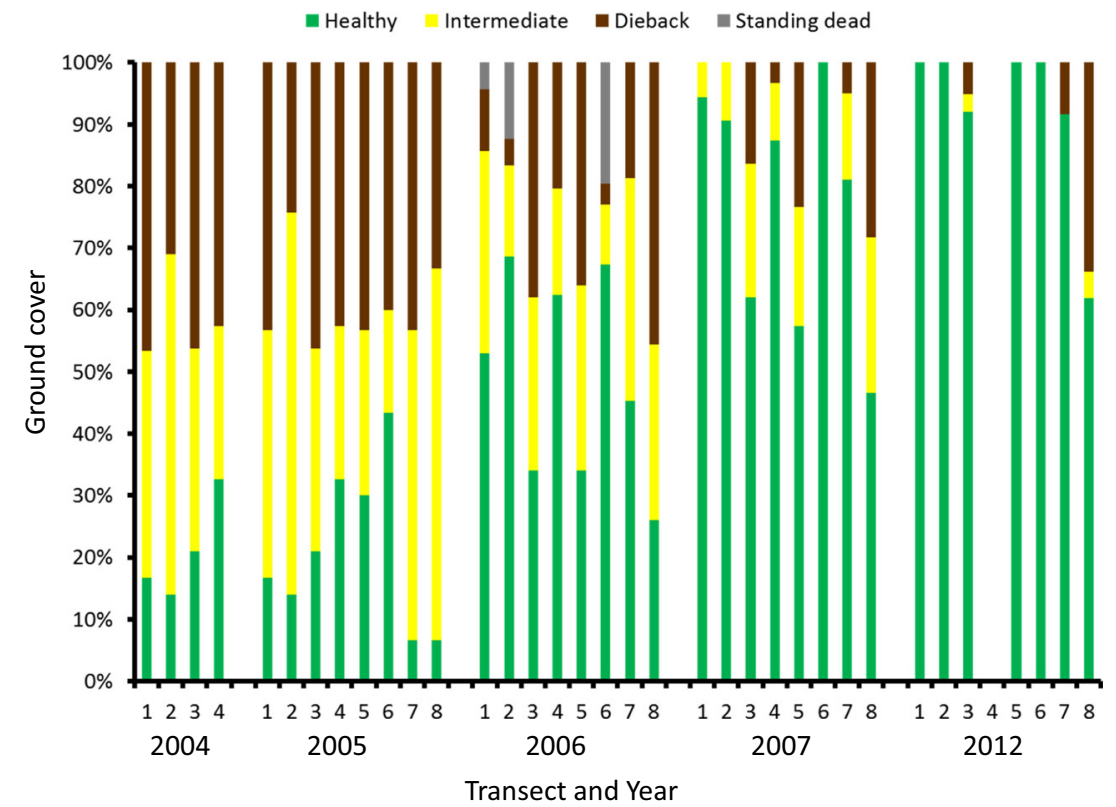

Fig. 3 Condition classes of sampled transects from 2004-2007 and 2012. In 2006, an additional category (standing dead) was added to account for several browned areas that occurred during that summer in 3 transects. Condition classes were categorized as 'dieback' if the ground cover of live and dead plants was $25 \%$ or less and $>75 \%$ was bare soil. It

years $(p<0.001)$ but not locations of duplicate sampling $(p=0.774)$ or interaction $(p=0.116)$. We used the post-hoc Bonferroni test to compare means of biomass in 2004 (dieback year) to other years. The 2004 live biomass was significantly lower than all but four years $(2002,2005,2006,2010)$ at $\alpha=0.1$ and different from 2001, 2003, and 2007, 2009 and 2011 at $\alpha=0.05$. Similarly, total biomass yielded significant differences among years $(p<0.001)$ but not locations of duplicate sampling $(p=0.780)$. Interaction between year and site was significant at $p=0.048$. Total EoYB from 2004 was the lowest measured $\left(486 \pm 219 \mathrm{~g}\right.$ dry mass $/ \mathrm{m}^{2}$ compared to a range of 527 in 2005 to 1143 and $1148 \mathrm{~g}$ dry mass $/ \mathrm{m}^{2}$ in 2003 and 2007, respectively) (Fig. 4). Bonferroni comparisons with 2004 showed significant differences from other years at $p<0.05$ for 2001, 2003, 2007 and 2011, although significant statistical interaction with site is noted. Two observations from these data are that a decrease in live biomass occurred in areas close to but not obviously in the dieback region and the recovery to nominal conditions occurred within 3 years.

Live EoYB was measured for each condition class within transects from 2004-2006 (Table 1). As obviously expected, there were differences reflecting condition class. There were statistically significant differences in the EoYB of live $S$. alterniflora among the condition classes $(p<0.001)$ and among years $(p=0.001)$ as analyzed as a mixed linear model for repeated measures. The live dry mass averaged over 3 years was lowest in the dieback $\left(26 \pm 37 \mathrm{~g} / \mathrm{m}^{2}\right)$, and highest in the healthy $\left(599 \pm 251 \mathrm{~g} / \mathrm{m}^{2}\right)$ with the intermediate condition having an average live mass between the two $\left(229 \pm 124 \mathrm{~g} / \mathrm{m}^{2}\right)$. was considered 'intermediate' from $26 \%$ to $85 \%$ live and dead plant cover. An area was considered 'healthy' at any plant ground cover over $85 \%$. In 2012, Transect 4 could not be located so no data is available for that year

There was an interaction between condition class*year $(p<0.001)$. However, the order of EoYB by condition class did not change over the years.

\section{Plant morphometrics}

Plant morphological traits changed with time over the growing season and condition class. As expected, plant height and leaves per tagged culm increased from June through August 2005. Across all classes, mean height ( \pm standard deviation) increased with statistical significance $(\mathrm{p}=<0.001)$ from $18.3 \pm 4.9 \mathrm{~cm}$ in early June to $25.3 \pm 7.3 \mathrm{~cm}$ in mid-August 2005. Heights of live culms in healthy areas averaged slightly more than $3 \mathrm{~cm}$ of those in intermediate or dieback areas, although this pattern was not statistically significant $(p=0.083)$ (Table 1). Number of leaves per tagged culm increased significantly with both time $(p<0.001)$ and condition class. By August, healthy culms had about 3 fewer leaves per culm than culms from intermediate and dieback condition classes $(p<0.001)$.

Non-tagged culms representative of each condition class were harvested in mid-August 2005 (Table 1). As with the tagged culms, heights did not differ between classes $(p=0.444)$, although no trend of taller culms from healthy areas was found. Number of leaves per culm had the same pattern as with tagged culms with healthy culms having about 3 fewer leaves than from other condition classes $(p<0.001)$. Differences in biomass per culm among condition classes were statistically significant at $p=0.04$ when biomass was 
Fig. 4 Long-term record of endof-year above ground biomass ( $\mathrm{g}$ dry mass $/ \mathrm{m}^{2}$ ) of Spartina alterniflora in low marsh of Upper Phillips Creek. Symbols correspond to mean plus and minus 1 standard deviation with circles indicating live culms and squares indicating total live plus standing dead

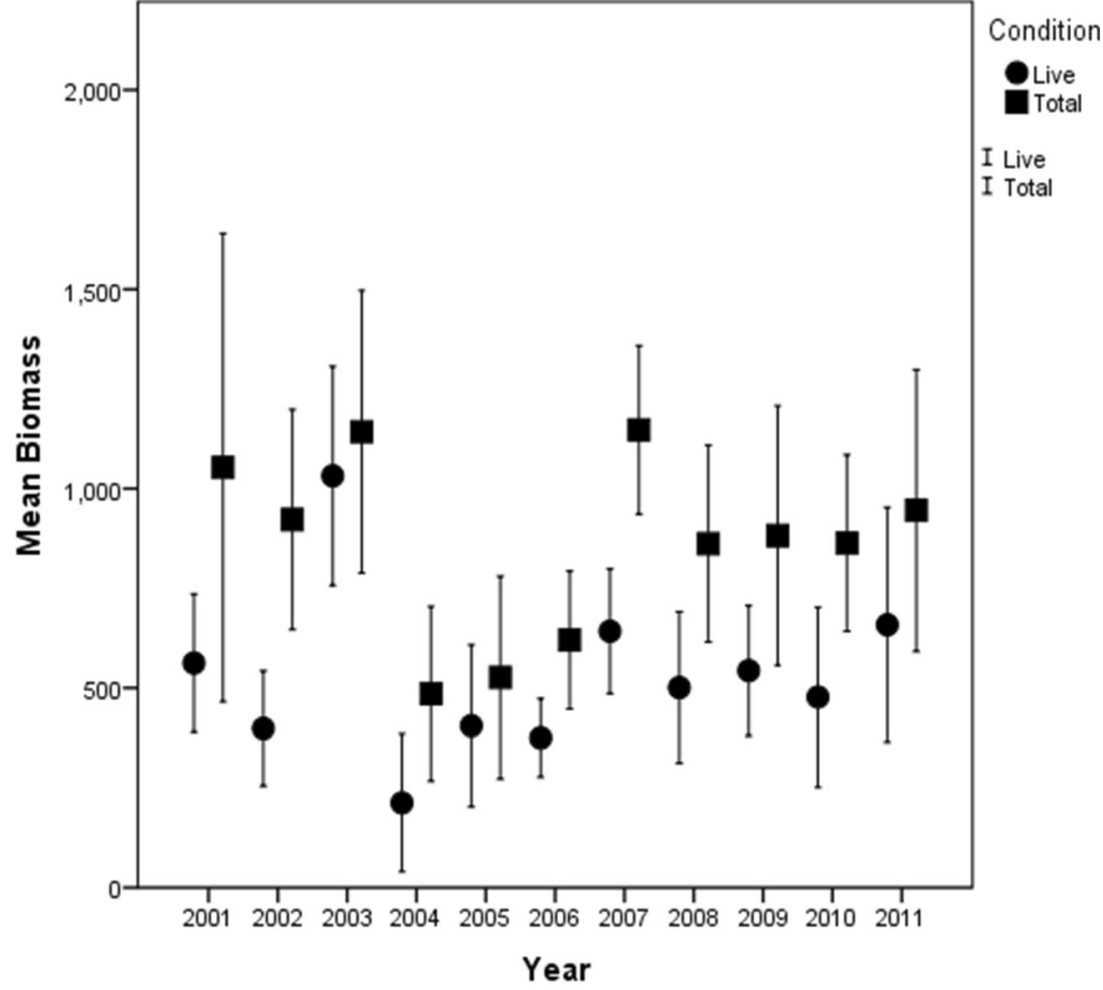

Error Bars: +/- $1 \mathrm{SD}$ $\log$ transformed to stabilize variance. Healthy condition class culms were $0.46 \pm 0.37 \mathrm{~g}$ per culm and weighed less than culms in both dieback $(0.60 \pm 0.48 \mathrm{~g}$ per culm $)$ and intermediate $(0.76 \pm 0.53 \mathrm{~g}$ per culm $)$ areas.

\section{Spectral analyses}

\section{Spectral band analyses of 2005 dieback transects}

Spectral response of green leaves was examined for surviving culms within condition classes (Fig. 5). Blue, green, red, and red-edge spectral bands, representing the visible response, each demonstrated statistically significant $(p<0.05)$ differences among transect T5, T6, T7, and T8 condition classes (Table 2). Just beyond visible wavelengths, NIR had no statistically significant differences in condition class $(p=0.067)$. In all bands leaves from the healthy condition class exhibited lower reflectance than leaves from the dieback class $(p<0.05$, through LSD pairwise comparisons). Reflectance of intermediate condition leaves was between values for the other two condition classes. Intermediate class blue and NIR bands were not significantly different from other condition classes.

Table 1 Differences among condition classes within transects: 'dieback' if the ground cover of live/dead plants was $\leq 25 \%$; 'intermediate' from $26 \%$ to $85 \%$ cover; and 'healthy' $>85 \%$ cover (mean \pm standard deviation)

\begin{tabular}{|c|c|c|c|c|c|}
\hline Variable & Units & Time & Healthy & Intermediate & Dieback \\
\hline \multirow[t]{3}{*}{ End of season live biomass in transects } & $\mathrm{g}$ dry mass $/ \mathrm{m}^{2}$ & 2004 & $590 \pm 311$ & $320 \pm 207$ & $14 \pm 22$ \\
\hline & $\mathrm{g}$ dry mass $/ \mathrm{m}^{2}$ & 2005 & $745 \pm 242$ & $223 \pm 64$ & $26 \pm 37$ \\
\hline & $\mathrm{g}$ dry mass $/ \mathrm{m}^{2}$ & 2006 & $457 \pm 144$ & $189 \pm 97$ & $35 \pm 43$ \\
\hline \multicolumn{6}{|l|}{ Tagged culms } \\
\hline Height & $\mathrm{cm}$ & August 2005 & $27.3 \pm 10.4$ & $25.3 \pm 7.3$ & $23.3 \pm 10.0$ \\
\hline Number of leaves per culm & No. & August 2005 & $6.1 \pm 1.9$ & $8.9 \pm 2.3$ & $9.0 \pm 2.0$ \\
\hline \multicolumn{6}{|l|}{ Harvested culms } \\
\hline Height & $\mathrm{cm}$ & August 2005 & $18.3 \pm 8.3$ & $21.6 \pm 6.7$ & $19.9 \pm 10.9$ \\
\hline Number of leaves per culm & No. & August 2005 & $6.2 \pm 1.8$ & $9.1 \pm 2.0$ & $9.3 \pm 1.8$ \\
\hline Biomass per culm & $\mathrm{g} /$ culm & August 2005 & $0.46 \pm 0.37$ & $0.76 \pm 0.47$ & $0.60 \pm 0.49$ \\
\hline
\end{tabular}



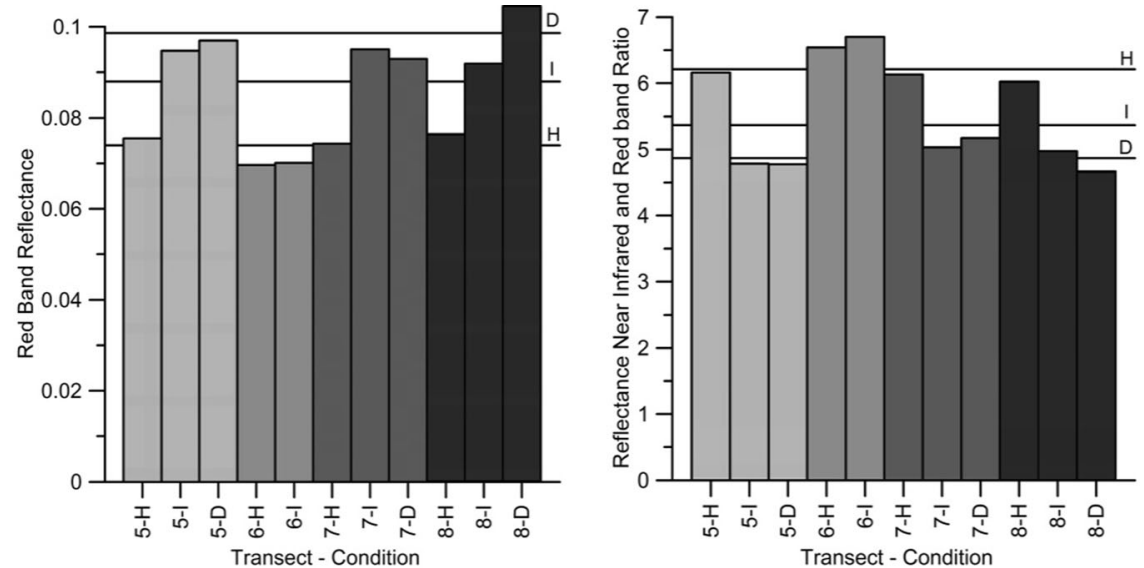

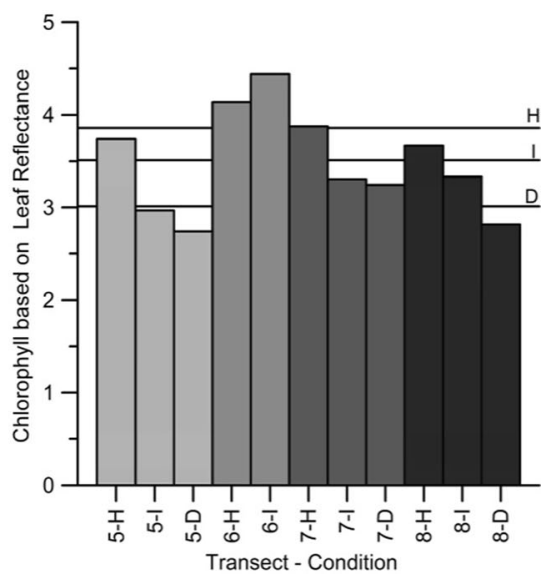

Fig. 5 Broadband spectral indicators of healthy $(\mathrm{H})$, intermediate (I), and dieback (D) marsh at transects T5, T6, T7, and T8 in 2005. The horizontal lines locate the $\mathrm{H}$, I, and D means of each condition class calculated from the 2005 transect samples shown in Table 2. These mean spectralcondition thresholds were used to validate and calibrate the relationship between spectral indicators and marsh condition in samples collected in

Differences in reflectance bands among condition classes as a percentage of the grand mean indicated that the red band provided the largest discrimination ability (averaging $56.8 \%$ of overall mean reflectance). Blue and green bands were next in their discrimination at approximately $40 \%$. Generally, there was good separation in visible reflectance between healthy and dieback with the largest differences being in the red band.
2007 at selected dieback transect sites and in marsh samples collected from 2004 to 2007 at sites B1-B4 located just outside the visually degraded dieback marsh extent. $\mathrm{X}$-axis labels represent the transect number and condition class (e.g., 5-H). Condition class by ground cover is defined in Fig. 3 legend and text

A progressive decrease in VI with condition class was best exhibited in the NIR-red reflectance ratio, whereas the difference in NIR-green ratios was not significant at $\mathrm{a}=0.05$ $(p=0.074$, Table 2$)$. Leaves from the healthy condition class had significantly higher NIR-red ratios than those from both dieback and intermediate condition classes while the ratio for leaves from the latter two classes were not statistically
Table 2 Spectral characteristics relative to condition class. Condition class and transect $p$ values are from two-way ANOVAs without replication. Bold values indicate statistically significant difference $(p \leq 0.05)$ from one other condition class using LSD pairwise comparison. Bold plus underlining indicates significant differences at $p \leq 0.01$ with two other condition classes. Pair differences are differences between condition classes as a percentage of the overall mean value. Pair differences provide a measure of discrimination of reflectance between condition classes, and these are calculated as percentages of the overall mean reflectance across condition classes. Total discrimination was indexed as the sum of the absolute values of the pair differences for each reflectance

\begin{tabular}{|c|c|c|c|c|c|c|c|c|c|}
\hline \multirow[t]{2}{*}{ Condition class } & & \multicolumn{8}{|c|}{ Spectral band reflectance, vegetation indicators or pigment } \\
\hline & & BLUE & GREEN & RED & RED EDGE & NIR & NIR/GREEN & NIR/RED & CHL \\
\hline & Condition class $\mathrm{p}=$ & 0.040 & 0.007 & 0.009 & 0.007 & 0.067 & 0.074 & 0.020 & 0.017 \\
\hline & Transect $\mathrm{p}=$ & 0.189 & 0.026 & 0.357 & 0.064 & 0.568 & 0.057 & 0.223 & 0.058 \\
\hline \multirow[t]{2}{*}{ Dieback } & Mean & 0.083 & $\underline{0.199}$ & 0.099 & $\underline{0.197}$ & 0.480 & 2.419 & 4.875 & $\underline{3.010}$ \\
\hline & Std. Deviation & 0.007 & 0.012 & 0.005 & 0.010 & 0.012 & 0.172 & 0.217 & 0.271 \\
\hline \multirow[t]{2}{*}{ Intermediate } & Mean & 0.078 & 0.176 & 0.088 & 0.178 & 0.465 & 2.678 & 5.374 & 3.510 \\
\hline & Std. Deviation & 0.011 & 0.023 & 0.012 & 0.018 & 0.012 & 0.417 & 0.891 & 0.641 \\
\hline \multirow[t]{2}{*}{ Healthy } & Mean & 0.067 & 0.164 & $\underline{0.074}$ & 0.166 & 0.459 & 2.814 & $\underline{6.214}$ & 3.855 \\
\hline & Std. Deviation & 0.004 & 0.013 & 0.003 & 0.006 & 0.005 & 0.215 & 0.226 & 0.206 \\
\hline \multirow[t]{2}{*}{ Overall } & Mean & 0.076 & 0.180 & 0.087 & 0.180 & 0.468 & 2.637 & 5.488 & 3.458 \\
\hline & Std. Deviation & 0.010 & 0.022 & 0.013 & 0.017 & 0.013 & 0.312 & 0.759 & 0.524 \\
\hline \multirow[t]{4}{*}{ Pair difference } & (D-H)/Overall & $20.8 \%$ & $19.5 \%$ & $28.4 \%$ & $17.0 \%$ & $4.5 \%$ & $-15.0 \%$ & $-24.4 \%$ & $-24.4 \%$ \\
\hline & (D-I)/Overall & $6.8 \%$ & $12.7 \%$ & $12.3 \%$ & $10.3 \%$ & $3.3 \%$ & $-9.8 \%$ & $-9.1 \%$ & $-14.5 \%$ \\
\hline & (I-H)/Overall & $13.9 \%$ & $6.8 \%$ & $16.1 \%$ & $6.7 \%$ & $1.2 \%$ & $-5.2 \%$ & $-15.3 \%$ & $-10.0 \%$ \\
\hline & Sum of absolute value of differences & $41.5 \%$ & $39.1 \%$ & $56.8 \%$ & $33.9 \%$ & $9.0 \%$ & $29.9 \%$ & $48.8 \%$ & $48.9 \%$ \\
\hline
\end{tabular}


different. The degree of NIR-red ratio discrimination based on differences as percentages of the grand mean was comparable to that found for the red band. Chlorophyll estimates progressively decreased from healthy to intermediate to dieback condition class with the dieback estimates (Table 2). The degree of discrimination was similar to that of the red band and NIRred ratio.

\section{Remeasurement at dieback transects in 2007}

Spectral analyses of plant samples collected in 2007 at selected transect condition locations occupied in 2005 provided an evaluation of the consistency of the spectral analyses, spectral condition indicators and an assessment of change (Fig. 6). All spectral indices show high consistency from 2005 to 2007. Healthy marsh in 2005 was again healthy in 2007. Only at transect site $6 \mathrm{H}$ did the 2005 chlorophyll concentration decrease from healthy to intermediate condition in 2007. Marsh condition classified as dieback in 2005 at transect site 7D improved to a healthy in 2007. Marsh at transect site 5D remained in the dieback condition in 2007. Although the spatial correspondence is not exact, the unchanged spectral classification aligns with independent site documentation that upwards of $23 \%$ of transect 5 remained in the dieback condition class in 2007. Overall, spectral results from 2007 were consistent with those established in 2005 and tracked observed changes in marsh condition from 2005 to 2007.

\section{Spectral analyses of marsh platform sites}

The red band, NIR/red VI, and chlorophyll pigment spectralbased indices had the highest discriminatory strengths in the 2005 spectral-condition. They revealed a marsh platform (B2B4) that underwent dramatic changes from 2004 through 2007 (Fig. 7). These sites were not obviously in the dieback area.
All platform sites (B2-B4) in 2004, but not the creekbank (B1), exhibited the lowest spectral-condition indices reflecting dieback to well below the dieback condition of the entire fouryear study (Fig. 7). In contrast, marsh in 2004 near the apex of the flushing tidal channel (B1) displayed a healthy spectralcondition. In 2005, all platform marsh was healthy based on the spectral-condition indexes. In 2006, field observations and measurements documented a dramatic decrease in live/dead biomass at site B1. That biophysically degradation at site B1 was reflected in the spectral indexes. Red band and NIR/red VI indexes at site B1 changed from healthy in 2005 to intermediate condition in 2006. Even more substantial change was reflected in the 2006 chlorophyll decrease in both platform and creekbank marshes. By 2007, the condition at all sites (B1-B4) improved to healthy.

\section{Discussion}

Dieback events within salt marshes of the USA appear to be occurring with increased frequency during the last couple of decades (Alber et al. 2008). We provide a case study of one dieback with an extensive array of measurements that accomplished the following: We classified three condition classes of ground cover that linked directly to both plant morphology and leaf spectral characteristics reflecting stress degree. Response variables are relevant to both in situ and remotely sensed monitoring programs. Potential environmental drivers of dieback initiation involving water availability were not obvious, and the influence of hurricanes potentiated. Evidence of stress in plants was seen beyond areas of obvious dieback. The associated spectral response offers opportunities for remote sensing of dieback potential. Resilience was documented at multi-year time and hectare spatial scales. Thus, we provide a broad perspective on the foundation species, S. alterniflora, affected by such an event.
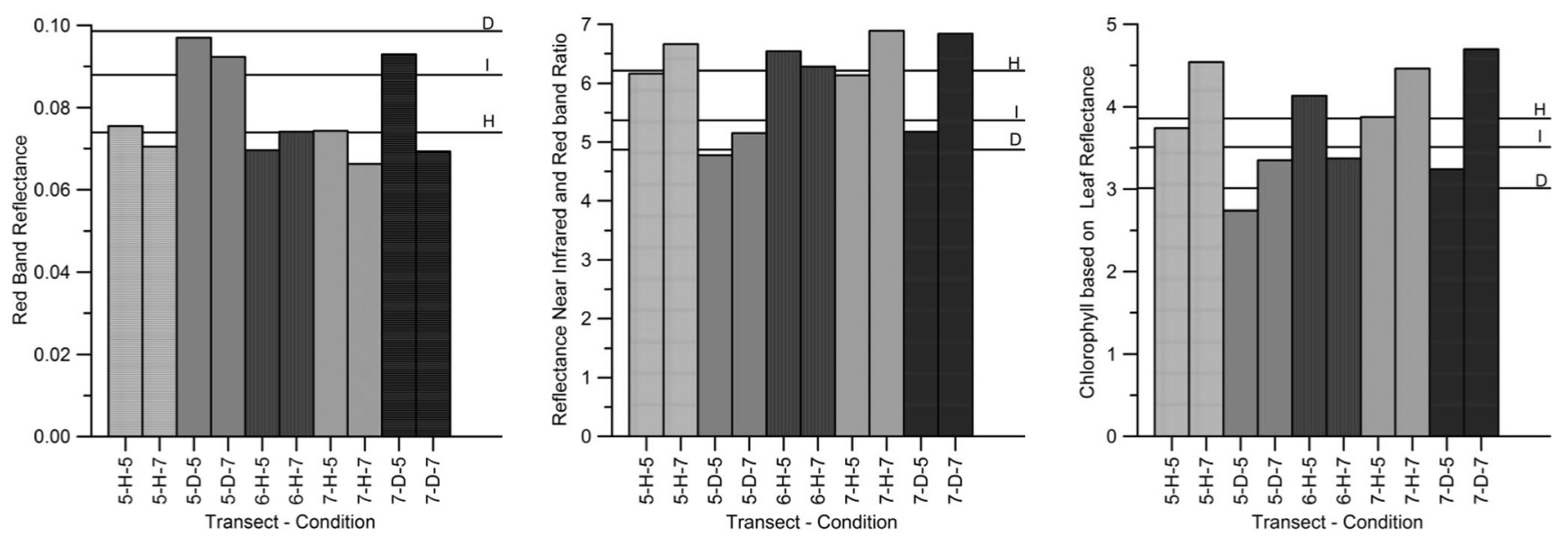

Fig. 6 Spectral indicators of marsh collected at the same transect locations in 2005 and 2007. Horizontal lines and condition labels are defined in Fig. 5. Samples are labeled on the $\mathrm{X}$-axis as transect $(5,6,7)$, condition class $(-\mathrm{H}$ or $-\mathrm{D})$ and year $(-5$ or -7$)$ 

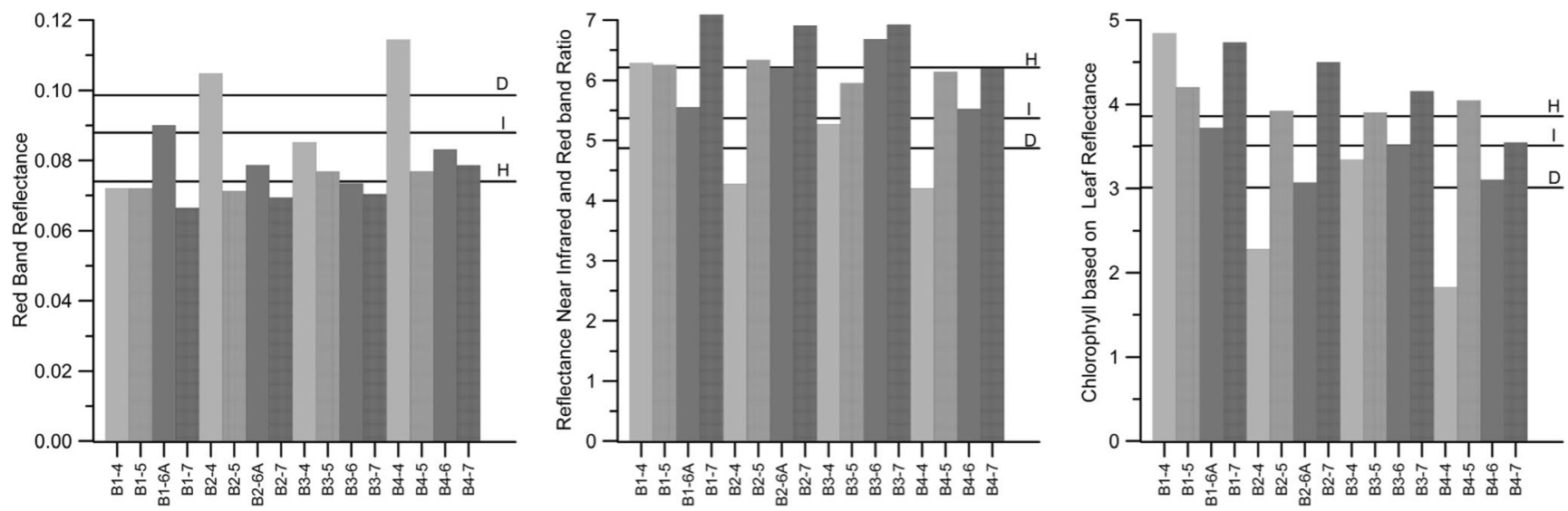

Fig. 7 Spectral for each of the four sites (B1-B4) for 2004, 2005, 2006, and 2007. The X-axis is labeled as the site and year (e.g., B1-4). Horizontal lines and condition labels are defined in Fig. 5

\section{Environmental drivers and initiation of sudden dieback}

As with many studies of dieback, most of our efforts occurred after the initiation of the dieback. However, because the UPC marsh is a component of the VCR-LTER program, we have pre-event and extended information on inundation frequency, precipitation and aboveground biomass for the area. One location for the routine EoYB study at the VCR-LTER serendipitously was the low marsh that was affected by the dieback. Means of both live and total EoYB for 2004 reflected the dieback by being the lowest among the years 2001 to 2011 . EoYB during the 3 years previous to 2004 did not give any foreshadowing of the dieback event.

Other, but not all, marsh sudden dieback events have been ascribed to decreased water availability and associated edaphic modifications (McKee et al. 2004; Alber et al. 2008; Hughes et al. 2012). In an intertidal salt marsh, water availability can be affected by drought conditions and low stages of sea level that reduce tidal flooding. We found that neither of these environmental drivers was particularly evident during 2003 or 2004 prior to the early summer dieback event. UPC is perched high in the tidal frame (Kirwan et al. 2012) and the frequency of tidal flooding is low (Fig. 2). Thus, at UPC $S$. alterniflora is subjected to a lower frequency of tidal flooding than often found (Morris et al. 2002; Voss et al. 2013). How this lower frequency may affect the resilience of $S$. alterniflora to stressors is unknown, although certainly there is evidence that the species can be productive with less than semi-diurnal flooding (Bertness 1991; Voss et al. 2013).

A regional environmental factor that may have had unexpected consequences on the VCR was Hurricane Isabel in September 2003. This storm produced a strong surge (Hovis et al. 2004). Inundation of seawater from Isabel deposited considerable particulate material in the low-to-high marsh transitional area, rapidly changed surface elevation on UPC marsh and killed trees neighboring the marsh (personal observation). Ramsey et al. (2012) found that high salinity associated with storm surge in Louisiana appeared to foster an immediate dieback but not necessarily a delayed one. We have no data on a specific mechanism for how the hurricane may have caused dieback in the subsequent year, but it is the only apparent, potentially significant environmental event preceding the dieback.

Other potential causes of dieback have been advanced. Silliman and colleagues (Silliman et al. 2005; Osgood and Silliman 2009) have suggested that herbivory may be an important contributor to dieback. Blum and Christian have studied this salt marsh for 20 years or more. No detailed census of potential herbivores such as Littoraria irrorata (marsh periwinkle) and Sesarma spp. (mud crab) have been conducted. However, neither has been found at even modest densities in the specific region of the dieback, and no evidence of an outbreak of such herbivores occurred in 2004 (personal observation). Subsequent estimates of density of snails in the different condition classes found only Melampus bidentatus (Marsh 2007) This species has not been associated with dieback elsewhere. A study of dieback in Atlantic salt marshes found a pathogenic fungi (Fusarium) in Spartina alterniflora samples taken from UPC marsh after the dieback event, although it did not appear that the pathogenic fungi play a primary causal role in dieback (Elmer and Marra 2011).

\section{Culms within condition classes}

Almost all variables demonstrated a differential response based on condition class (Table 3). Condition class was defined operationally with decreasing plant cover from healthy to intermediate to dieback areas. Thus, it is not surprising that aboveground S. alterniflora biomass per unit area tracks condition class. What is more interesting is the ways that condition class exhibited itself in other measurements.

Living culms were found in all three condition classes with differences among classes. Live culms in the healthy condition class tended to have the fewest leaves. And culms in 
Table 3 Summary of results. Condition classes are healthy (H), intermediate (I) and Dieback (D) based on \% vegetation cover as described in text

\begin{tabular}{|c|c|c|c|c|}
\hline Approach & Variable & Location & Time & Results \\
\hline \multirow[t]{2}{*}{ Environmental drivers } & Frequency of tidal flooding & Low marsh & 1997-2009 & Above average in 2003, below average in 2004 \\
\hline & $\begin{array}{l}\text { Precipitation in growing } \\
\text { season }\end{array}$ & Region & 1986-2009 & Above average in 2003 and 2004 \\
\hline \multirow[t]{2}{*}{ End of season harvesting } & \multirow[t]{2}{*}{ Above ground biomass } & Low marsh & 2001-2007 & Lowest in 2004, no indication of problem in 2003 \\
\hline & & Transects & 2004-2006 & $\mathrm{H}>\mathrm{I}>\mathrm{D}$ all years \\
\hline \multirow[t]{4}{*}{ Ground cover } & \multirow[t]{3}{*}{ Vegetation condition } & \multirow[t]{3}{*}{ Transects } & \multirow[t]{3}{*}{ 2004-2007, 2012} & D decreased from 42 to $10 \%(2004-2007)$ \\
\hline & & & & $\mathrm{H}$ increased from 21 to $77 \%$ (2004-2007) \\
\hline & & & & H increased to $92 \%$ in 7 transects (2012) \\
\hline & Bare area & Central & 2005, 2006, 2012 & Bare area decreased $3 \%$ by 2006 and $98 \%$ by 2012 \\
\hline \multirow[t]{3}{*}{ Culms } & Height & Transects & 2005 & $\mathrm{H}=\mathrm{I}=\mathrm{D}$ \\
\hline & Number of leaves per culm & Transects & 2005 & $\mathrm{H}<\mathrm{I}=\mathrm{D}$ \\
\hline & Biomass per culm & Transects & 2005 & $\mathrm{H}<\mathrm{I}=\mathrm{D}$ \\
\hline \multirow[t]{3}{*}{ Spectral analysis of green leaves } & Red band change & Transects & 2005 & $\mathrm{H}<\mathrm{I}=\mathrm{D}$ \\
\hline & Vegetation index/red & Transects & 2005 & $\mathrm{H}<\mathrm{I}=\mathrm{D}$ \\
\hline & Chlorophyll change & Transects & 2005 & $\mathrm{H}=\mathrm{I}>\mathrm{D}$ \\
\hline
\end{tabular}

dense healthy areas were thinner (i.e., less mass per cm height) compared to those found in isolated clusters within dieback areas. S. alterniflora culms are well known to demonstrate morphological plasticity associated with different environmental conditions, such as flooding regime, nutrient supply and light penetration (Valiela et al. 1978; Wiegert and Freeman 1990; Proffitt et al. 2005). We postulate that the thinner culms with fewer leaves in healthy areas were subject to more density dependence and related light limitation than the clusters of culms surviving in dieback and intermediate areas. Also, leaf absorbance of photosynthetically active radiation tended to be lowest in culms from the dieback condition (i.e., reflectance was greatest) even though the healthiest leaves on each sampled culm were selected. As with morphology, plasticity of spectral conditions in S. alterniflora has been recognized (Ramsey and Rangoonwala 2005).

S. alterniflora culms often represent ramets of clones (Shumway 1995), although individual clones may be interspersed providing genetic diversity within a few meters distance (Proffitt et al. 2005). Isolated clusters of culms within the dieback or intermediate classes may thus be part of the same clone. The connection of these ramets to each other or to dead ramets, however, was not determined. It is conceivable that the responses seen in the culms of the dieback and intermediate condition classes may not only reflect stress on the culms themselves. The responses may reflect the loss or stress of other ramets within the clone (Schwarzschild and Zieman 2008).

\section{Recovery and resilience}

Previous dieback studies have revealed various degrees of recovery and resilience over multiple years through the reestablishment of S. alterniflora in previously disturbed areas (de
Souza and Yoch 1997; McKee et al. 2004; Ogburn and Alber 2006). The variables that were followed through time showed a trajectory toward recovery after 2004. The percentages of ground cover in the various condition classes remained similar between 2004 and 2005. Percentage in dieback class decreased and percentage in healthy class increased from 2005 to 2006 and from 2006 to 2007. In 2006, however, relatively small areas of standing dead S. alterniflora culms were scattered throughout the area, perhaps indicating a minor dieback. By 2012, recovery was almost complete, although an area toward the high marsh had a mottled appearance of bare patches and shallow pools that we associate with ongoing transgression of the marsh (Brinson et al. 1995). By 2012, the primary evidence of the main dieback area was a small (approximately 4-m diameter) patch of bare soil near the center of the original dieback. EoYB within three years after 2004 returned to masses similar to those prior to 2004, with the exception of an unusually high biomass in 2003. Thus, the engineering resilience time was of the order of 3 years, while ecological resilience was demonstrated by return to the original ecosystem state of a $S$. alterniflora dominated low marsh within a similar time frame (sensu Holling 1996).

The reduction in the central dieback area appeared to be the result of rhizomal ingrowth from edges adjacent to healthy and intermediate areas. Little growth occurred from within this dieback area. However, we did not assess the nature of reintroduction of culms into the dieback areas within transects. They could have arisen from clonal ingrowth, seeds or healthy rhizomes within the dieback areas (Proffitt et al. 2005).

Local elevations (at $\mathrm{m}^{2}$ scale) within transects decreased by centimeters from healthy to dieback condition classes by 2006. A negative influence of subsidence and elevation loss can be inferred during recovery after dieback in Louisiana, but 
on a larger scale than ours (Baustian et al. 2012). The UPC marsh has little slope, and small changes in elevation may have localized impact on flooding duration. Further, the overall elevation is high in the tidal frame and frequency of flooding, even in the low marsh, is limited (Fig. 2a). Even slight depressions within areas of the dieback condition class may allow water to pool locally and increase duration of submergence with tidal flooding. Increased duration of submergence can lead to a loss in vegetation due to changes in edaphic factors, including waterlogging and greater reduced conditions (Mendelssohn and McKee 1988). It is unknown, however, if the dieback areas had lower elevations at the time of the occurrence or if the differences in elevation are a result of plant decomposition and subsequent erosion or loss of turgor within roots with concomitant peat collapse. DeLaune et al. (1994) showed that peat collapse rather than erosion caused the conversion of marsh to open water in an area of marsh that died. They posited that peat collapse following plant death may originate from an increase in the decomposition rate of root tissue and loss of root turgor. This is plausible for UPC.

\section{Spectral responses to dieback and implications for remote sensing}

Marsh condition classes based on ground cover were supported by spectral response (Tables 2 and 3). The most effective spectral-condition indicators reflected changes in the red wavelengths followed by the vegetation index (VI) based on the near-infrared and red ratio. The selection of the red-based spectral-condition indicators is consistent with the late stage of marsh dieback used in spectral calibration (e.g., Gitelson et al. 2003). It also concurs with Ramsey and Rangoonwala (2005) who showed that later stages of marsh dieback were most reliably aligned with the chlorophyll absorption peak, which was correlated best with red reflectance. Red band, NIR/red VI, and chlorophyll indicators derived from leaf spectral measurements of marsh at different stages of dieback distinctly reflected changes in marsh condition as classified by biophysical measures. The alignment of biophysical measures and spectral indicators of marsh condition is a critical result of this study and confirms the direct relationship between marsh condition during a dieback event and spectral indices directly amenable to remote sensing. We used the three spectral indicators from dieback, intermediate, and healthy condition classes in 2005 to establish spectral-condition thresholds for marsh status (Table 2). These thresholds were assessed in the following three ways.

Confirmation of the robustness of the spectral indicators in detecting and tracking marsh condition was obtained from analyses of plant-leaf samples collected along transects in the dieback marsh in 2005 and 2007. Of the 15 comparisons across the three spectral indicators, 11 demonstrated the same condition class for both 2005 and 2007. Only four showed a change in class across years. One of the four occurred when chlorophyll indicated healthy class in 2005 but intermediate class in 2007 (Fig. 6). The remaining three of the four changes were for all three indicators at one site. The indicators showed dramatic improvement in condition at a site in transect 7 , which was classified as dieback in 2005 (Fig. 6). Independent biophysical measurements confirmed that marsh at that site had improved from the dead class in 2005 to the healthy class in 2007 , exactly tracking the spectral-condition indicator change.

The three spectral indicators were also calculated for plantleaf samples collected from three platform sites and one creekbank marsh site from 2004 to 2007 (B designated sites in Fig. 1a). In 2004 none of the four sites visually exhibited signs of marsh dieback. However, the spectral indexes calculated for these non-dieback platform areas indicated stress. This supported the EoYB results in the area. The ability of the spectral indicators to document coordinated changes in marsh condition at multiple sites located in two separate marsh areas is a critical result of this study. The alignment of spectral results between dieback and non-dieback areas combined with the proven robustness of the thresholds in a 2005 to 2007 comparison demonstrates the effectiveness of the spectral thresholds to quickly assess marsh condition status. These spectral indicators are amenable to ground data gathering with new and small-size portable instruments and possibly extendable to satellite remote sensing data platforms.

A third line of evidence corroborating the utility of the spectral indicators was the capture of conditions resembling a small-scale dieback in 2006, two years after the dieback peak. While the change in spectral indicator magnitudes did not revert to dieback levels, they suggested a downturn in marsh condition. In addition to the spectral indicators, field measures documented an increase in dead marsh composition at the head of the tidal flushing channel, and a decrease in endof-year biomass and new standing dead in transects. Thus, spectral indicators had independently detected the change in marsh condition, and provided a measure of degradation intensity. Measured against the thresholds, the decline to intermediate condition, while not yet reaching the dieback threshold, indicated the approach's potential to predict marsh decline.

The relationship of spectral indices applied in this study and the dieback progression was directly comparable to relationships found in the Louisiana dieback study using the same spectral indices (Ramsey and Rangoonwala 2005). However, the overall spectral spectral indicator magnitudes of the Louisiana and of this study differed. A higher range of magnitudes was found for the red band reflectance and lower ranges tended to incorporate the NIR/red VI and chlorophyll pigment concentration in the Louisiana marsh dieback than found in this study. The Louisiana study encompassed more frequently flooded $S$. alterniflora marsh in contrast to the 
S. alterniflora marsh of the UPC. This suggests the functionality of the spectral indices as estimators of dieback condition is consistent; however, regional calibration of the spectralcondition index magnitudes may be needed to accommodate different regions.

\section{Conclusions}

The ecosystem services provided by salt marshes are jeopardized by sudden dieback events. Loss of services may be temporary if the marshes can recover or permanent should ecological resilience be overcome and a new ecosystem state, such as a mudflat, develop. S. alterniflora is a foundation species for many salt marshes. Its culms provide (1) baffling to reduce water flow and retain sediments, (2) photosynthetic products to promote belowground growth and subsequent peat, (3) food for the detrital food web, and (4) habitat for a variety of animals (Peterson et al. 2008). Sudden dieback events are most readily evidenced by decline in live culms and aerial biomass. However, as we have shown, evidence of a problem can also be found in plants outside the obvious area of dieback. Further, some live culms often remain in dieback areas, and these are also affected. The scientific community does not have the understanding required to predict the onset, severity and recovery from sudden marsh dieback. In fact the dieback of marsh plants may be a general symptom of several potential stressors and facilitators (Alber et al. 2008; Osgood and Silliman 2009; Elmer et al. 2013). Understanding of this phenomenon needs to be built upon case studies of dieback across a range of locations, species and intensities. Our study provides one such case study and contributes significantly through the comprehensiveness of environmental, biophysical and spectral measurements and assessment of context through long-term studies.

Condition class designations based on ground cover served as good representatives for a variety of dieback response variables. These relationships provide opportunities for effective monitoring for dieback and perhaps other stressor responses. Spatial patterns found in spectral variables coincide closely with those of morphological conditions and biomass distribution. Leaves of culms from dieback areas had clear patterns of stress within their spectra. We developed the spectral thresholds of condition class and found them useful in interpreting marsh condition beyond dieback, including the potential to predict marsh decline. The spectral indicators of condition may be especially germane to remote sensing.

The recovery process lagged for a year after initial dieback and proceeded in the second year to near nominal after 3 years. However, a small residual area remained 8 years after dieback. These patterns should provide expectations for the study of other dieback events. And temporal patterns support plant stress during 2004 (and to a lesser extent 2006), although no clear evidence of stress from drought or infrequent tidal flooding was seen. The only environmental anomaly was the occurrence of Hurricane Isabel in fall 2003, but the mechanisms of any relationship to dieback were not investigated. Thus, the dieback in UPC is characterized by the symptoms seen in other marshes but may not have a similar cause.

Acknowledgments This work was supported in-part by National Science Foundation grants DEB-0080381 and DEB-0621014 to the Virginia Coast Reserve Long-term Ecological Research site. Partial support for this work was provided under U.S. Geological Survey Hurricane Sandy Supplemental Funds (AE03FBK, GX13SC00FBK). We thank The Nature Conservancy, and in particular Barry Truitt, for access to UPC and their general willingness to support science on their property. We also thank the numerous staff, students and volunteers who contributed their time and effort to support this project. We thank Dr. Charles Bachmann at the Naval Research Laboratory (NRL), Washington D.C. and Dr. Arthur Schwarzschild at the Anheuser-Busch Coastal Research Center for providing financial and facilities support. Any use of trade, firm, or product names is for descriptive purposes only and does not imply endorsement by the U.S. Government.

Open Access This article is distributed under the terms of the Creative Commons Attribution 4.0 International License (http:// creativecommons.org/licenses/by/4.0/), which permits unrestricted use, distribution, and reproduction in any medium, provided you give appropriate credit to the original author(s) and the source, provide a link to the Creative Commons license, and indicate if changes were made.

\section{References}

Alber M, Swenson EM, Adamowicz SC, Mendelssohn IA (2008) Salt marsh dieback: an overview of recent events in the US. Estaurine, Coastal, and Shelf Science:1-11

Baustian JJ, Mendelssohn IA, Hester MW (2012) Vegetation's importance in regulating surface elevation in a coastal salt marsh facing elevated rates of sea level rise. Glob Chang Biol 18:3377-3382

Bertness MD (1991) Zonation of Spartina patens and Spartina alterniflora in a New England salt marsh. Ecology 72:138-148

Bertness MD, Silliman BR (2008) Consumer control of salt marshes driven by human disturbance. Conserv Biol 22:618-623

Bertness MD, Brisson CP, Bevil MC, Crotty SM (2014) Herbivory drives the spread of salt marsh die-off. PLoS One 9:e92916

Blum LK (1993) Spartina alterniflora root dynamics in a Virginia marsh. Mar Ecol Prog Ser 102:169-169

Brinson MM, Christian RR, Blum LK (1995) Multiple states in the sealevel induced transition from terrestrial forest to estuary. Estuaries 18:648-659

Carter G, Knapp A (2001) Leaf optical properties in higher plants: linking spectral characteristics to stress and chlorophyll concentrations. Am J Bot 88:677-684

de Souza MP, Yoch DC (1997) Spartina alterniflora dieback recovery correlates with increased acetylene reduction activity in saltmarsh sediments. Estuarine, Coastal, and Shelf Science 45:547-555

DeLaune RD, Nyman JA, Patrick WH (1994) Peat collapse, ponding, and wetland loss in a rapidly submerging coastal marsh. J Coast Res 10 : $1021-1030$ 
Elmer WH, Marra RE (2011) New species of Fusarium associated with dieback of Spartina alterniflora in Atlantic salt marshes. Mycologia 103:806-819

Elmer WH, LaMondia JA, Caruso FL (2012) Association between Fusarium spp. on Spartina alterniflora and dieback sites in Connecticut and Massachusetts. Estuar Coasts 35:436-444

Elmer WH, La Mondia JA, Useman S, Mendelssohn IA, Schneider RW, Jiménez-Gasco MM, Marra RE, Caruso FL (2013) Sudden vegetation dieback in Atlantic and gulf coast salt marshes. Plant Dis 97: 436-445

Gitelson A, Kaufman Y, Merzlyak M (1996) Use of a green channel in remote sensing of global vegetation from EOS-MODIS. Remote Sens Environ 58:289-298

Gitelson A, Gritz Y, Merzlyak M (2003) Relationships between leaf chlorophyll content and spectral reflectance and algorithms for nondestructive chlorophyll assessment in higher plant leaves. J Plant Physiol 160:271-282

Holdredge C, Bertness MD, Altieri AH (2008) Role of crab herbivory in die-off of New England salt marshes. Conserv Biol 23:672-679

Holling CS (1996) Engineering resilience versus ecological resilience. In: Engineering within ecological constraints. National Academy of Engineering, Washington, DC, pp. 31-44

Hovis J, Popovich W, Zervas C, Hubbard J, Shih HH, Stone P (2004) Effects of hurricane Isabel on water levels: data report. NOAA Technical Report NOS CO-OPS 040

Huete AR (2012) Vegetation indices, remote sensing and forest monitoring. Geography Compass 6:513-532

Hughes ALH, Wilson AM, Morris JT (2012) Hydrologic variability in a salt marsh: assessing the links between drought and acute marsh dieback. Estuar Coast Shelf Sci 111:95-106

Keusenkothen MA, Christian RR (2004) Responses of salt marshes to disturbance in an ecogeomorphological context, with a case study of trampling by deer. In: Fagherazzi S, Marani M, Blum LK (eds) In The Ecogeomorphology of Tidal Marshes. American Geophysical Union, Washington, DC, pp. 203-230

Kirk J (1994) Light \& Photosynthesis in Aquatic Ecosystems, Second edn. Cambridge University Press, Cambridge and New York

Kirwan ML, Christian RR, Blum LK, Brinson MM (2012) On the relationship between sea level and Spartina alterniflora production. Ecosystems 15:140-147

LI-COR (1984) LI-1800UW underwater spectroradiometer instruction manual, LI-COR Publication No. 8405-0037, LI-COR Inc., Lincoln, Nebraska

Marsh AC (2007) Effects of a salt marsh ecosystem following a Brown marsh event, Master's thesis. East Carolina University Department of Biology, Greenville, NC

McKee KL, Mendelssohn IA, Materne MD (2004) Acute salt marsh dieback in the Mississippi River deltaic plain: a drought induced phenomenon. Glob Ecol Biogeogr 13:65-73

Mendelssohn IA, McKee KL (1988) Spartina alterniflora die-back in LA: time-course investigation of soil waterlogging effects. J Ecol 76:509-521

Morris JT, Sundareshwar PV, Nietch CT, Kjerfve B, Cahoon DR (2002) Responses of coastal wetlands to rising sea level. Ecology 83:28692877

Ogburn MB, Alber M (2006) An investigation of salt marsh dieback in Georgia using field transplants. Estuar Coasts 29:54-62

Osgood D, Silliman BR (2009) From climate change to snails: potential causes of salt marsh die-back along the U.S. Eastern Seaboard and Gulf Coasts. In: Silliman BR, Grosholtz T, Bertness MD (eds) In Human Impacts in Salt Marshes: A Global Perspective. University of California Press, Berkeley

Penuelas J, Filella I (1998) Visible and near-infrared reflectance techniques for diagnosing plant physiological status. Trends Plant Sci $3: 151-156$
Peterson CH, Able KW, DeJong CF, Piehler MF, Simenstad CA, Zedler JB (2008) Chapter 4. Practical proxies for tidal marsh ecosystem services: application to injury and restoration. Adv Mar Biol 54: 221-266

Proffitt CE, Chiasson RL, Owens AB, Edwards KR, Travis SE (2005) Spartina alterniflora genotype influences facilitation and suppression of high marsh species colonizing an early successional salt marsh. J Ecol 93:404-416

Ramsey E III, Rangoonwala A (2004) Determining the optical properties of the narrow, cylindrical leaves of Juncus roemerianus. IEEE Geosci Remote Sens 42(5):1064-1075

Ramsey E III, Rangoonwala A (2005) Leaf optical property changes associated with the occurrence of Spartina alterniflora dieback in coastal Louisiana related to remote sensing mapping. Photogramm Eng Remote Sens 71:299-311

Ramsey E III, Rangoonwala A (2006) Site-specific canopy reflectance related to marsh dieback onset and progression in coastal Louisiana. Photogramm Eng Remote Sens 72:641-652

Ramsey E III, Rangoonwala A (2010) Mapping the onset and progression of marsh dieback. In: Wang Y (ed) In Remote Sensing of Coastal Environments, Remote Sensing Applications Series. CRC., Boca Raton, pp. 123-129

Ramsey E III, Werle D, Suzuoki Y, Rangoonwala A, Lu Z (2012) Limitations and potential of optical and radar satellite imagery to monitor environmental response to coastal emergencies in Louisiana, USA. J Coast Res 28:457-476

Schneider RW, Useman S (2005) The possible role of plant pathogens in Louisiana's brown marsh syndrome. In: Proceedings of the 14th Biennial Coastal Zone Conference, July 17 to 21, 2005. LA, New Orleans

Schrift AM, Mendelssohn IA, Materne MD (2008) Salt marsh restoration with sediment-slurry amendments following a drought-induced large-scale disturbance. Wetl 28:1071-1085

Schwarzschild AC, Zieman JC (2008) Effects of physiological integration on the survival and growth of ramets and clonal fragments in the seagrass Syringodium filiforme. Mar Ecol Prog Ser 372:97-104

Shumway SW (1995) Physiological integration among clonal ramets during invasion of disturbance patches in a New England salt marsh. Ann Bot 76:225-233

Silliman BR, van de Koppel J, Bertness MD, Stanton LE, Mendelssohn IA (2005) Drought, snails, and large-scale die-off of southern U.S. salt marshes. Science 310:1803-1806

Smith S (2009) Multi-decadal changes in salt marshes of Cape Cod, MA: photographic analyses of vegetation loss, species shifts, and geographic change. Northeast Nat 16:183-208

Spectron Engineering, Inc. (n.d.) Operating Manual: SE590 Fieldportable Data Logging Spectroradiometer, Spectron Engineering, Denver, Colorado

Valiela I, Teal JM, Deuser WG (1978) The nature of growth forms in the salt marsh grass Spartina alterniflora. Am Nat 112:461-470

Voss CM, Christian RR, Morris JT (2013) Marsh macrophyte responses to inundation anticipate impacts of sea-level rise and indicate ongoing drowning of North Carolina marshes. Mar Biol 160:181-194

Webb EC, Mendelssohn IA (1996) Factors affecting vegetation dieback of an oligohaline marsh in coastal LA: field manipulation of salinity and submergence. Am J Bot 83:1429-1434

White SN, Alber M (2009) Drought-associated shifts in Spartina alterniflora and $S$. cynosuroides in the Altamaha River estuary. Wetlands 29:215-224

Wiegert, R.G. \& Freeman, B.J. (1990). Tidal salt marshes of the southeast Atlantic coast: A community profile. U.S. Fish and Wildlife Service, Biological Report no. 85 (7.29). 